\title{
Measuring and Assessing the Evolution of Liquidity in Forward Natural Gas Markets: The Case of the UK National Balancing Point
}

\author{
Lilian M. de Menezes*, Marianna Russo**, and Giovanni Urga***
}

\begin{abstract}
Following the development of natural gas trading hubs in Europe, forward products have become a response to the higher exposure to price risk faced by energy companies. Yet, a significant share of trade occurs over-the-counter (OTC), where inter-dealer brokers act as intermediaries and deals may be customized. Hence, there are concerns about transparency and market quality, of which liquidity is a main indicator. This study investigates liquidity in the largest one-month-ahead European forward market for natural gas in the period from May 2010 to December 2014, using asynchronous high-frequency data and time-varying measures of spread and price impact from the financial market microstructure literature. The usefulness of these measures in the seasonal and evolving National Balancing Point (NBP) is assessed and different aspects of liquidity and transaction costs are unveiled.
\end{abstract}

Keywords: Liquidity measures, natural gas markets, over-the-counter trading, time-varying modeling

http://www.example.com

\section{INTRODUCTION}

Liquidity can be defined as the ability to match buyers and sellers at the lowest transaction costs (O'Hara, 1995). This definition impounds a dynamic feature of the markets and implies that in a liquid market, executing a transaction over a short-time horizon does not entail higher costs than spreading the same transaction over a longer horizon. It also evokes the concept of elasticity, such that small shifts in the fundamental values of demand and supply result in negligible price changes when liquidity is high. Consequently, in a liquid market trading activity affects pricing only in a transient and marginal way (Hasbrouck, 2007), and the likelihood of uncompetitive behaviors and price manipulation is reduced. By contrast, illiquidity is a barrier to market entry and a source of competitive disadvantage, mainly to smaller players. Hence, measuring liquidity is critical when assessing market quality.

In the context of evolving European natural gas markets, how best to measure and assess liquidity has become increasingly relevant, not only to those interested in the cost of hedging and investment decisions, but also to regulators and policy makers, who need to monitor market quality. The liberalization process, by increasing the exposure of market participants to demand-supply imbalances, has fostered the development of forward markets and a move away from the traditional oil-indexed long-term contracts towards hub (spot) pricing. According to IGU (2016), the share of volumes traded indexed to hub prices rather than oil prices has quadrupled in the previous ten years. Greater

*Faculty of Management, Cass Business School, City, University of London.

${ }^{* *}$ Corresponding author. Economic and Social Research Institute and Trinity College, Department of Economics. Faculty of Finance, Cass Business School, City, University of London. Send correspondence to Whitaker Square, Sir John Rogerson's Quay, Dublin 2 D02 K138, Ireland. E-mail: marianna.russo@esri.ie

${ }^{* * *}$ Faculty of Finance and Centre for Econometric Analysis (CEA@ Cass), Cass Business School, City, University of London. Department of Management, Economics and Quantitative Methods, Università di Bergamo, Italy. 
competition and forward trading have also encouraged the participation of financial institutions (investment banks, hedge and pension funds, and trading companies), which have further contributed to the development of hub trading. Yet, the interest of market participants in trading an asset depends upon its value, as well as on the market mechanisms and costs underlying the trading process (Harris, 2003; Hasbrouck, 2007). As natural gas trading garners increasing interest in the European markets, liquidity measurement is relevant when investigating price dynamics, and has implications for efficiency, welfare and regulation of the trading mechanisms and market structure.

This paper measures and assesses the evolution of liquidity in the OTC forward market at the UK National Balancing Point (NBP, hereafter), which is the most mature hub for natural gas trading in Europe (Cummins and Murphy, 2015, EC, 2015). One-month-ahead forward contracts are considered, as these are the most frequently traded contracts and thus representative of the European natural gas forward market. Using tick-by-tick indicative quotes, transaction prices and volumes from 2010 to 2014, measures of spread and price impact that are drawn from the financial market microstructure literature are estimated. These measures allow for an examination of the transactional properties of the one-month-ahead NBP forward market and the likely effects of trading activity on prices. Therefore, this study also evaluates whether such measures, which have been designed and applied in financial markets, are applicable to the physical natural gas markets. A time-varying approach is adopted, with the intent of addressing the evolving hub trading and exploring changes in market liquidity that might have occurred over the sample period.

The remainder of the paper is organized as follows. In Section 2 the literature on liquidity measurement in financial and energy markets is reviewed. Section 3 focuses on the data and the empirical methods used to assess the liquidity dynamics in the one-month-ahead NBP forward market. The results are reported in Section 4 and discussed in Section 5. Section 6 concludes the paper.

\section{MEASURING LIQUIDITY IN FINANCIAL AND ENERGY MARKETS}

\subsection{Liquidity Measurement in Financial Markets}

As per Kyle (1985), liquidity encompasses different transactional properties of a market: tightness, defined as the cost of turning around a position over a short period of time; depth, that is the size of a traded volume innovation required to change the price by a given amount; and resiliency, or the speed at which prices recover from a random shock. Overall, these properties highlight the dynamic feature of liquidity, which reflects the transaction costs carried by investors to complete a transaction.

According to market microstructure theory, transaction costs include three components, namely order-processing costs, inventory costs and asymmetric-information costs (Stoll, 1978: Harris, 2003), and can have different impacts on asset prices. Order-processing costs refer to commissions, fees, taxes and other certain costs in a transaction.

The intuitive meaning of inventory costs is derived from a microstructure model where customers trade only with the market-maker, i.e. an institution or individual that quotes both bid and ask prices in a financial instrument, e.g. futures and forward contracts. Market-makers (e.g. London Stock Exchange, New York Stock Exchange) are normally required to provide sufficient liquidity to the market in order to reduce price volatility and guarantee market efficiency. They trade to make a market, rather than for their own investment reasons, and are subject to uncertainties concerning the future transaction price and volume of an asset. Hence, market-makers assume the risk of holding a certain amount of a particular asset, i.e. inventory risk, in order to provide liquidity to the market and facilitate the trading process of such an asset (Demsetz, 1968; Stoll, 1978, Amihud and Mendelson, 1980, 1986). Inventory costs, therefore, represent the market-maker's compensation for bearing the risk of supplying immediate liquidity; they are different from the physical cost of storage (i.e. carrying costs, such as building and facility maintenance related costs, insurance, financing costs) and influence the asset price temporarily (Stoll, 1978). 
An adverse selection problem emerges in the presence of traders that are better informed about the asset fair value (Bagehot, 1971, Glosten and Milgrom, 1985). Informational-based trading is a risk faced by uninformed traders, since the gains of the informed traders are the losses of the uninformed traders. Consequently, asymmetric-information costs can arise in the market, and reflect a balancing of gains and losses due to the presence of informed traders (O'Hara, 1995, p.56). These costs have a permanent effect on the asset price and the quantity that can be traded at any given price (Easley and O'Hara, 1987). In contrast to order processing costs, inventory costs and asymmetric-information costs are more difficult to measure and are associated with the transactional properties of a market. As such, they are linked to market liquidity, and may be inferred from measures of market liquidity. Since investors consider liquidity when making investment decisions, inventory costs and asymmetricinformation costs have implications for hedging and the effectiveness of portfolio-diversification strategies. Several measures of spread have been introduced in the financial literature to investigate market tightness, and discriminate between inventory and asymmetric-information costs. Different econometric approaches have been also used to make inferences about the relative contributions of transaction costs and their implications for liquidity. Furthermore, given the link between liquidity, trading activity and asset prices, several measures and approaches have been adopted to evaluate the impact of trading activity on prices, and thus assess market depth and resilience. These approaches and measures are reviewed below.

\subsubsection{Measures of spread}

Different measures of spread have been adopted in the financial literature, and are mainly devoted to capture the tightness of a market. The most commonly used measures of spread are the quoted bid-ask spread and the effective spread (e.g. Chordia et al., 2000; Bessembinder, 2003, Goyenko et al. 2009, Foucault et al., 2013). The bid-ask spread is the difference between the best ask price and the best bid price, and represents the transaction cost paid by a customer to the market-maker for a round-trip, i.e. a purchase followed by a sale of the same amount. This measure of spread is associated with inventory costs (Roll, 1984, Stoll, 1989), nonetheless it can overstate the actual transaction costs if: the market-maker (i.e. a participant who undertakes to buy and sell at specific prices in a market) adjusts the bid-ask spread to control the inventory level; or, in the presence of asymmetric-information (Stoll, 1989). Moreover, in the over-the-counter (OTC) markets, where a centralized trading platform is absent, buy and sell trades are negotiated through inter-dealer brokers. Although the bid and ask quotes are posted by the inter-dealers based on actual trading orders and expressions of interest, they are not binding(Jankowitsch et al., 2011). As a result, transaction prices can be different from the bid and ask quotes, thus the quoted bid-ask spread can be a misleading measure of market tightness in OTC markets.

The effective spread was introduced in the financial literature as an alternative to the quoted bid-ask spread and provide a more reliable measure of tightness. It reflects transaction prices that are negotiated either inside or outside the indicative quotes (Huang and Stoll, 1996) and is computed as the difference between the actual transaction prices and the average of the bid and ask quotes, namely the midquote, which is a proxy for the asset fair value (Bessembinder, 2003, Foucault et al. 2013). Since the midquote is a basis to evaluate whether the buyer is paying a high price and the seller is receiving a low price, the effective spread can be totally ascribed to trading process, thus measuring transaction costs in the market. This fact has been exploited by Goyenko et al. (2009), who introduced a measure of spread defined by midquote changes to assess the informational component in the effective spread, based on the norm that the asset value reduces in response to seller-initiated trades and increases in response to buyer-initiated trades (Kyle, 1985, Brennan and Subrahmanyam. 1996). Yet, the effective spread also includes inventory costs. As explained by Stoll (1978), the intuition behind inventory costs, which represent the non-informational component of the effective spread, is that the transaction costs should lead to a temporary deviation of the asset price from its fair

Copyright (C) 2016 by the IAEE. All rights reserved. 
value. This non-informational component follows a post-transaction price reversal and is measured by the realized spread, which is the difference between transaction price and post-transaction midquote (Amihud and Mendelson, 1980, Bessembinder and Venkataraman, 2010).

In all, the effective spread has been proved to be a reliable measure of transaction costs, thus suitable for liquidity assessments in OTC markets. Other measures of spread, such as the the realized spread and the measure proposed by Goyenko et al. (2009) have been also used in the financial literature to capture inventory costs and asymmetric-information costs, and thus provide insights on the liquidity dynamics (e.g. Chordia et al. 2000, Goyenko et al. 2009). In addition to these measures of spread, statistical and econometric approaches have been adopted to quantify the relative contribution of each cost component. These approaches are based on the theoretical expectation of market microstructure that trading activity has different impacts on prices, depending upon the prevalence of inventory costs, asymmetric-information costs or order processing costs.

\subsubsection{Measuring the relative contribution of the different transaction costs}

Roll (1984) focused on a serial covariance estimator of the transaction prices to make inferences on the cost components of the bid-ask spread. Subsequent research used covariance models to measure the relative contributions of order processing costs, inventory costs and asymmetric-information costs in the spread (Choi et al., 1988). A different class of models used buyer-initiated and seller-initiated trades to infer the relative impact of these costs on prices (Glosten and Harris, 1988; Stoll, 1989, Hasbrouck, 1991; Madhavan et al., 1997).

The econometric approach proposed by Huang and Stoll (1997) represents, however, the first attempt to measure the relative contribution of all the three components of the transaction costs in an unified way, by exploiting the information unveiled in the trading activity. Specifically, their "three-way decomposition" model moves from the assumption that informational-based trading should be revealed by serial correlation in the trade direction (i.e buyer-initiated and seller-initiated trade), and by imbalances between buyer-initiated and seller-initiated trades. Order processing costs are therefore identified, and the permanent component of the price changes, which is attributable to the asymmetric-information costs, can be discriminated from the transitory component, which is driven by the inventory costs. In summary, the approach by Huang and Stoll (1997) overcame some limitations of the measures of spread in the previous subsection, which are mostly focused on one component of transaction costs, and may neglect measurements of order processing costs. Yet, it still does not allow for inferences on the impact of trading activity on prices and, thus on the depth and resilience of a market. Different measures and approaches have been used in literature to evaluate the price impact, and are reviewed below.

\subsubsection{Measures price impact}

The price impact captures the pressure exerted by the trading activity on the asset prices, which depends on the traded volumes (Kyle, 1985; Easley and O'Hara, 1987). The serial covariance estimator of the transaction prices by Roll (1984) measures this impact by assuming that, if markets were efficient (Fama, 1991), prices would fully reflect all the available information on the asset fair value. In which case, their serial covariance should be zero when the transaction costs are negligible while a negative serial covariance entails positive transaction costs. However, this measure of price impact is only unbiased for large sample sizes, or when changes in prices are uncorrelated with the trading process and inventory costs are zero (Huang and Stoll, 1997).

Amihud (2002) developed a measure to capture the impact of one-dollar of traded volume on prices, and Brennan and Subrahmanyam (1996) introduced a measure of price impact defined by the magnitude of price changes associated with the order flow, i.e. the difference between buyer-initiated and seller-initiated trades. In a similar vein, Pastor and Stambaugh (2003) focused on the expected return 
reversals associated with the signed volume, which is a measure of traded volume that discriminates between buyer-initiated and seller-initiated trades. Their measure follows from the expectation that low liquidity is accompanied by a high volume-related return reversal. Hence, impulse response functions can determine the speed of convergence of price changes towards their equilibrium after unexpected traded volumes. This is the rationale for the approach taken by Hasbrouck (1991), and more recently by Banti et al. (2012). Yet, prices adjust to the information impounded in the traded volumes gradually and thus may not be immediately revised to reflect public information. To overcome the issue of the price adjustment to information over time, Hasbrouck (2009) measured price impact as the price changes associated with the cumulative signed volume over a fixed time interval, thus allowing for inferences on the pressure exerted on prices by larger trades, which are often executed in multiple transactions.

The measures of price impact that were described above exploit the fact that trading activity has a different impact on asset prices, depending on the transaction costs (Foucault et al., 2013), and have been thus used to investigate the depth and resilience of financial markets. Consequently, measures of spread and price impact contribute to the assessment of the transactional properties of a market and its liquidity dynamics.

\subsection{Liquidity Measurement in Energy Markets}

Like in financial markets, liquidity in energy markets, can be regarded as a sign of a grounded market. In particular, for an energy trader "the presence of good liquidity in a market signifies an important reassurance that he is not alone, that he will be able to find a counterparty when he needs to adjust his position, that the bid to offer price spread will be manageable and that the reference or index price used in that market is credible" (Peter Styles, Chairman of the Electricity Committee at the European Federation of Energy Traders, February 14, 2013) 1 Therefore, measuring liquidity in energy markets is crucial when assessing their quality.

Practitioners in natural gas and electricity markets usually refer to the churn ratio when measuring liquidity. This measure is the ratio of traded volumes to physical deliveries after the transactions: the higher this ratio, the greater is liquidity. Yet, in natural gas markets, traded volumes are weatherdependent, and this seasonal component can impact the churn ratio. As illustrated in Figure 1 , on average greater churn ratio is observed in the summer (July-September), when the traded volumes are lower compared to the winter months. As the level of storage grows in the summer (Timera, 2016), one may conjecture that physical deliveries reduce relative to financial trading, thus driving the churn ratio up. The churn ratio can also increase because of higher level of financial trading due to efforts to rebalance portfolios in the light of unexpected changes in the natural gas demand. Most importantly, the churn ratio does not provide information about the transactional properties of the market.

When considering the literature on commodity and energy markets, measures of spread appear to have been first used by Locke and Venkatesh (1997) when investigating liquidity in the Chicago Mercantile Exchange (CME) futures market and, more recently, by Marshall et al. (2012) and Marshall et al. (2013) to assess the liquidity of commodity futures comprising the S\&P Goldman Sachs Commodity Index and its link with stock market liquidity. Furió et al.(2009) used a measure of depth defined as the ratio of the demanded electricity to the offered electricity to evaluate liquidity risk in the Spanish power market, whilst Bevin-McCrimmon et al. (2016) relied on the traded volume and the open interest, and on the measure by Amihud (2002) to investigate the link between liquidity and risk premia in the New Zealand power market. In the European context, Weber (2010) adopted price-demand functions as measures of price-impact to investigate liquidity in the German power market, while Frestad (2012) used the quoted bid-ask spread to evaluate the effectiveness and cost of hedging strategies in the Nordic power market. A measure of bid-ask spread based on flexible generating capacity was introduced by Hagemann and Weber (2013) to assess liquidity determinants

\footnotetext{
${ }^{1}$ https://www.euractiv.com/section/energy/opinion/energy-markets-and-policymakers-in-search-of-liquidity/
} 
Figure 1: Monthly NBP traded volumes and churn ratio

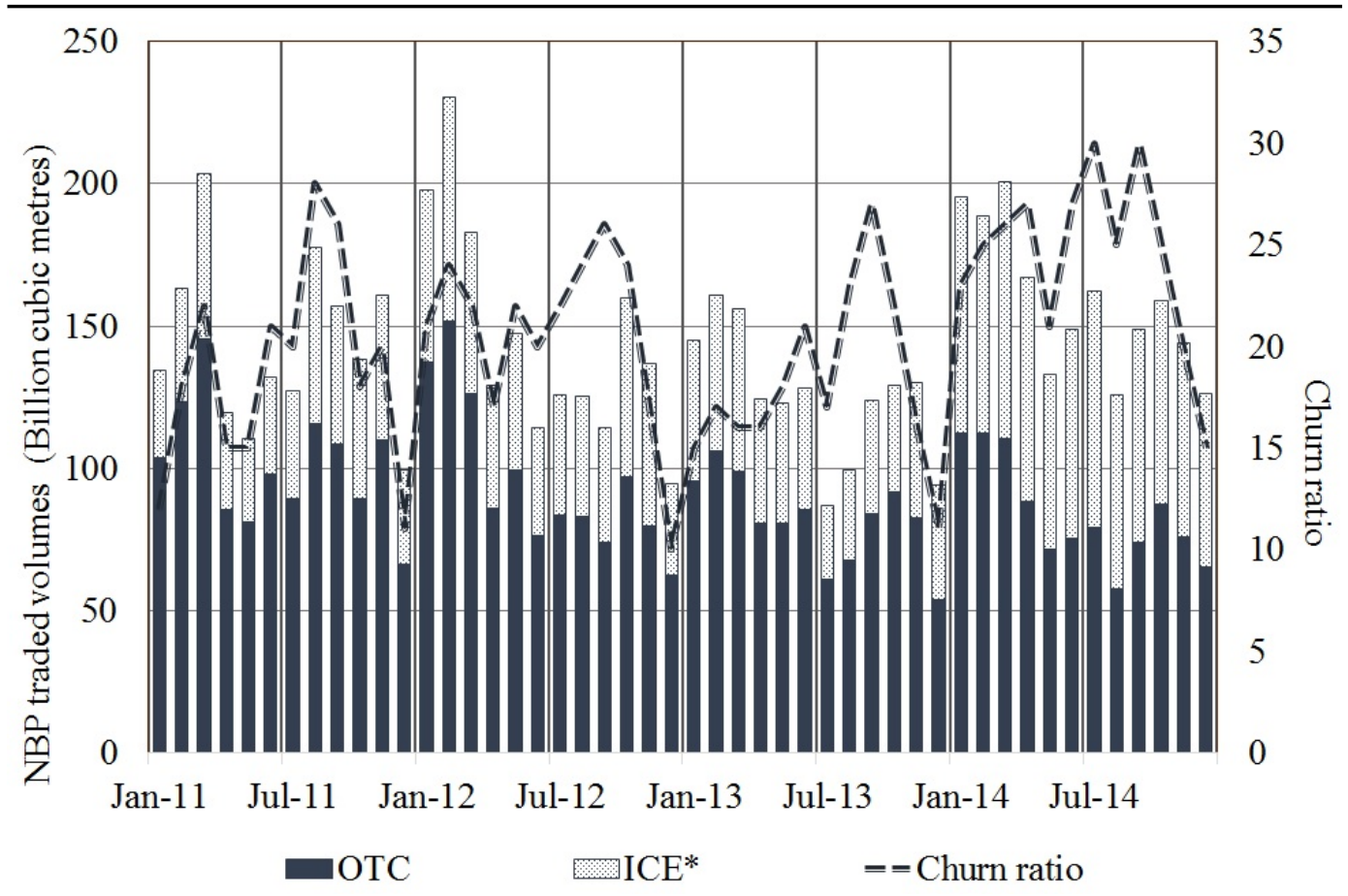

*Includes ICE Endex data. Source: Ofgem-Data portal

in the German power market. By contrast, Neuhoff et al. (2016) relied on the difference between the volumes at the highest and lowest possible electricity prices to measure depth in the German power market.

In all, different measures have been employed in literature to investigate liquidity in energy markets. However, to date, a comprehensive assessment of the transactional properties of energy markets implied by liquidity, i.e. tightness, depth and resilience, and measurements of the relative contributions of the different transaction costs appear to have been neglected. As a result, how best to measure and assess the evolution of liquidity in energy markets is a research question that, to the best of our knowledge, remains to be addressed in the context of natural gas markets.

\section{THE STUDY}

Given the limitations of the literature concerning liquidity measurement in energy markets, and the questions posed by the churn ratio as a practical measure of liquidity, in this study the perspective of the financial market microstructure literature is adopted. Measures of spread and econometric approaches are used to investigate market tightness and the contribution of the different components of transaction costs to liquidity in the one-month-ahead NBP forward market. In addition, measures of price impact are adopted to evaluate the pressure exerted by the trading activity on prices and make inferences about the market's depth and resilience.

\subsection{Data}

Records of transactions and quotes for the NBP forward contracts over the period from 7 May, 2010 to 29 December, 2014 are considered. These were made available by Tullett Prebon Information (http://www.tpinformation.com/indepthdata/commoditiesenergy.aspx), which is part of the TP ICAP group and an international provider of independent real-time price information from the global OTC 
financial and commodity markets.

The sample covers about a third of the total OTC market for the NBP in the period. Two data sets are considered: the first includes tick-by-tick indicative quotes, corresponding to 350,889 observations; the second includes tick-by-tick transaction prices and volumes, totalling 110,774 observations. In order to account for the asynchronous nature of the tick-by-tick data, a stepwise cleaning procedure is adopted, which is based on Brownlees and Gallo (2006) and Barndorff-Nielsen et al. (2009). Holidays, weekends, errors and outliers are deleted. For transactions and quotes, the trading window from 7:00 to 17:00 (GMT) on standard working days (Monday-Friday) is considered. Simultaneous records are aggregated in a single record: quotes and transactions are measured by their median; while, volumes and transaction prices are aggregated by using their respective totals.

Following Barndorff-Nielsen et al. (2009), outliers are detected via a non-parametric distance-based approach. Entries for which the bid-ask spread is greater than 10 times the median spread of that day are discarded. Similarly, entries are deleted if the midquote, which as defined above is the average of bid and ask quotes, deviates by more than 10 median absolute deviations from the median midquote on that day. Records are also deleted when the transaction price is negative and when the absolute relative deviation of the transaction price from the prevailing midquote is more than 10 times the median of the absolute relative deviations in the sample. This smooths the trade data using prevailing bid and ask quotes. Similar to Lee and Ready (1991), last quotes are defined as quotes occurring at least 5 seconds before the trade.

Month-ahead NBP futures and forward contracts are for delivery in fixed calendar months (e.g. one-month-ahead contracts on March 15, 2014 are for delivery in April 2014). These contracts cease trading two business days prior to the first calendar day of the delivery month (ICE, 2017). Therefore, entries corresponding to transactions recorded during the roll-over period, i.e. after the end of the trading period and before delivery, have been discarded. Overall, the data cleaning results in discarding less than $13 \%$ observations. Together, the cleaning and subsequent alignment of each transaction to the prevailing midquote results in 69,787 observations, which are recorded at trading time. The data are then sampled at regularly spaced time-intervals.

According to Foucault et al. (2013), regular time intervals are required to ensure that prices have adjusted to the information content of the cumulative transactions over time. Similar to Zhang et al. (2005) and Boffelli and Urga (2015), the trading window is split into fixed-time intervals. For each time interval, the following information is extracted: the end-of-interval price, the end-of-interval quotes, the end-of-interval trading volume, the total trading volume over the interval, the total trade size over the interval, and the total number of transactions over the interval. When a time interval does not contain observations, the most recent recorded observation is used. Finally, in the spirit of Boffelli and Urga (2015), the first record of each day is excluded from the sample, because it could reflect the adjustment to the overnight information and thus exhibit excessive variability, when compared to the other observations in the same day. This resampling procedure is performed at different frequencies: $5,15,30$, and 60 minutes. The aim is to identify the best behaved sample to be analyzed, which minimizes volatility clustering, kurtosis and autocorrelation in the midquote and transaction price return series.

\subsection{Measuring Liquidity in the One-Month-Ahead NBP Forward Market}

\subsubsection{Measures of spread}

The effective half-spread is computed to measure tightness in the market. It can be considered in absolute basis points, or as a percentage of the midquote. In this study, the percentage effective half-spread (EHS) is adopted, because percentage measures are more common in the literature and permit comparison between different assets (e.g. Chordia et al., 2000). The percentage effective 
half-spread is defined as follows:

$$
E H S_{\tau}=D_{\tau}\left(\frac{P_{\tau}-M_{\tau}}{M_{\tau}}\right)
$$

where $P_{\tau}$ is the price of the $\tau^{t h}$ transaction, evaluated at the trading time, $M_{\tau}$ is the midquote prevailing at each transaction. $D_{\tau}$ is the trade indicator taking values 1 for buyer-initiated transactions, and -1 for seller-initiated transactions. In the financial literature (e.g. Goyenko et al., 2009, Foucault et al., 2013), this indicator is usually set according to the algorithm by Lee and Ready (1991): A transaction is classified as buyer-initiated if its transaction price is closer to the prevailing ask quote than bid quote, and as seller-initiated otherwise. If a transaction is priced exactly at the midquote, it is buyer-initiated when its price is higher than the price of the previous transaction ("uptick"); conversely, it is classified as seller-initiated ("downtick").

Since the effective half-spread measures both the inventory costs and the asymmetric-information costs related to the trading process, the percentage realized half-spread (Amihud and Mendelson. 1980; Bessembinder and Venkataraman, 2010) is also computed in order to evaluate the inventory costs, i.e. the non-informational and temporary component of the effective spread. The percentage realized half-spread (RHS) is defined as follows:

$$
R H S_{\tau}=D_{\tau}\left(\frac{P_{\tau}-M_{\tau+1}}{M_{\tau}}\right)
$$

where $M_{\tau+1}$ represents the midquote after the transaction, used as a proxy for the post-transaction value of the asset. The realized half-spread can also be interpreted as the effective half-spread net of the asymmetric-information costs, i.e. it excludes both the informational and permanent components (Foucault et al., 2013).

Following Goyenko et al. (2009) and focusing on the midquote-change after a transaction as a proxy for the permanent price-change, the informational component of the effective spread is captured by:

$$
P I_{\tau}=D_{\tau}\left(\frac{M_{\tau+1}-M_{\tau}}{M_{\tau}}\right)=E H S_{\tau}-R H S_{\tau} .
$$

The measures in Eq1/3 are thus computed to examine the transactions costs in the one-month-ahead NBP forward market, allowing for an assessment of both the inventory and informational components. In order to evaluate the relative importance of each component of the transaction costs, the econometric approach in Huang and Stoll (1997) is also used in this study, and is described below.

\subsubsection{Estimating the relative contributions of the transaction costs to the spread}

The "three-way decomposition" proposed by Huang and Stoll (1997) allows to estimate the relative importance of order processing costs, inventory costs and asymmetric-information costs in the one-month-ahead NBP forward market. A regression of the log-returns obtained from the transaction prices (hereinafter referred to as returns) on the contemporaneous and lagged measure of order flow is estimated. This measure is given by the trade indicator $D_{t}$ defined above, computed over a fixed time-interval $t, t=1, \ldots, T$, and accounts for the aggregated information impounded in the order-arrival over the interval. Following Huang and Stoll (1997), it is assumed to be generated by a first-order autocorrelated process, i.e.:

$$
D_{t}=\varphi D_{t-1}+\eta_{t}
$$

where $\eta_{t}$ is a white noise error term $\left(\right.$ i.e. $\left.\mathrm{E}\left(\eta_{t}\right)=0, \forall t ; \mathrm{E}\left(\eta_{t} \eta_{s}\right)=0, \forall t \neq s ; \operatorname{Var}\left(\eta_{t}\right)=\sigma^{2}<\infty\right)$. The autocorrelation $\varphi$ implies that investors react similarly to an informative event, thus creating 
a flow of orders on the same direction. By contrast, when inventory risk is considered, a negative autocorrelation should be observed in the order flow, which stems from adjustments in inventory level and induces return-reversals (i.e. positive returns followed by negative returns and vice versa) (Stoll, 1978; Foucault et al., 2013). Nonetheless, investors may prefer to reduce the impact of large-size transactions on prices by executing them through a series of smaller orders. In short, a positive autocorrelation should be observed in the order flow.

Regardless of its sign, this autocorrelation incorporates the predictable component of the order flow and only its unexpected component, which contains new information, should be allowed to affect the transaction prices. Consequently, based on Huang and Stoll (1997), the relationship between order flow and returns is as follows:

$$
r_{t}=\gamma \Delta D_{t}+(\alpha+\beta) \gamma D_{t-1}-\alpha \gamma \varphi D_{t-2}+\varepsilon_{t}
$$

where $r_{t}=\ln \left(\frac{P_{t}}{P_{t-1}}\right)$ is return series obtained from the transaction price $P_{t}, \Delta D_{t}=D_{t}-D_{t-1}$ and $\gamma$ represents a constant effective spread, i.e. the constant market tightness. Hence, in the spirit of Huang and Stoll (1997), by jointly estimating Eq 4 and Eq 5, the relative contributions of each transaction cost to this spread is measured: $\alpha$ represents the relative amount of spread due to asymmetric-information costs; $\beta$ reflects the inventory costs; and $(1-\alpha-\beta)$ measures the relative importance of the order-processing costs. Finally, the error term captures the effects of public information other than trades (e.g. macro-economic factors, business cycles). Estimation is carried out using the generalized method of moments (GMM) and the Newey-West estimator to accommodate serial correlation and heteroscedasticity in the error term.

\subsubsection{Measuring the price impact}

The three measures of spread described above can explain the cost-components of a single small transaction. However, liquidity adjusts to the pressure exerted by large-size transactions and imbalances between buyer-initiated and seller-initiated traded volumes (Kyle, 1985, Easley and O'Hara, 1987, Hasbrouck, 2009). This adjustment is not captured by the "three-way decomposition", since this decomposition only considers the impact of the trade-direction on prices. It does not allow for inferences on the relationship between traded volumes and prices, and the extent to which tradedvolume imbalances affect the transaction prices, as per definition of market depth above.

In order to investigate the one-month-ahead NBP forward market depth, a measure of price impact is used in this study, which is a slight modification of the one proposed by Hasbrouck (2009). It links the returns to the cumulative signed volumes, i.e. the cumulative traded-volume imbalances over fixed time intervals. However, differently from Hasbrouck (2009), the physical volume, rather than its monetary value, is used. IN addition, the estimate is allowed to be time-varying, so that changes in the relationship between imbalances and returns can be observed. The price impact measure adopted in this study is defined as the time-varying coefficient $\lambda_{n}$ in the following linear regression model:

$$
r_{n, t}=\lambda_{n} S_{n, t}+u_{n, t}
$$

where $r_{n, t}=\ln \left(\frac{P_{n, t}}{P_{n, t-1}}\right)$ is the return series from transaction price $P_{n, t}$ over a fixed time interval $t$, in the rolling window $n ; S_{n, t}=\sum_{\tau} D\left(v_{n, t, \tau}\right) \sqrt{v_{n, t, \tau}}$ is the signed square-root of the traded volumes in the same interval and rolling window; $D\left(v_{n, t, \tau}\right)$ is the trade indicator, $v_{n, t, \tau}$ is the traded volume and $\tau$ indexes the transactions in the fixed time interval $t$ and rolling window $n ; u_{n, t}$ is the white noise error term, such that $\mathrm{E}\left(u_{n, t}\right)=0, \forall t ; \mathrm{E}\left(u_{n, t} u_{n, s}\right)=0, \forall t \neq s ; \operatorname{Var}\left(u_{n, t}\right)=\sigma^{2}<\infty$. The time-varying coefficient $\lambda_{n}$ is estimated using rolling windows of size $m$ over the full sample of size $T$. Increments between successive rolling windows of one unit of time are used, thus leading to $N=T-m+1$ estimates of the coefficient $\lambda_{n}$ over the full sample. This measure of price impact is in the spirit of Kyle 
(1985), since its reciprocal, $\frac{1}{\lambda_{n}}$, captures the depth of the market, and also allows for inferences on market resilience: the lower the value of $\lambda_{n}$, the less sensitive the prices to traded-volume imbalances, the higher is the market depth, and its resilience.

In summary, the measures of spread are used to assess the dynamics of the one-month-ahead NBP forward market tightness: the effective spread $E H S$, and its inventory (RHS) and informational $(P I)$ costs components. The "three-way decomposition" is also used in order to infer the relative impact of order processing costs, inventory costs and asymmetric-information costs on prices, and thus to provide a more comprehensive assessment of the transaction costs in the market. Finally, the time-varying measure of price impact $\lambda_{n}$ is estimated to investigate the evolution of the one-month-ahead NBP forward market depth, and make inferences about the pressure exerted by the trading activity on prices and market resilience.

\subsection{Deseasonalizing and Detrending Liquidity Measures}

Given the seasonality and trend that can be observed in the time series, it is important to ensure that predictable market activity variation affecting the variables in a similar way are removed. In other words, the focus of the analysis is on the irregular component (the residual series). Following, Chordia et al. (2005), the raw time series $y$ is regressed on a set of adjustment variables, $X$, which in this study are: 11 month-of-the-year dummies (February - December); 4 day-of-the-week dummies (Tuesday-Friday); a time-trend. In order to standardize the estimated residuals, the following regression is computed:

$$
\log \left(\hat{u}^{2}\right)=X \gamma+v
$$

and the adjusted time series to be analyzed is:

$$
\tilde{y}=a+b\left(\frac{\hat{u}}{\exp (X \hat{\gamma} / 2)}\right),
$$

where $a$ and $b$ are set so that raw and adjusted sample means and variances are the same. Consequently, units of measurement of original and adjusted time series are the same.

\subsection{Preliminary Data Analysis}

Descriptive statistics of the series resampled at different frequencies $(5,15,30$ and 60 minutes) are reported in Table 1 . Number of observations ( $N$ in column two) and observations per day ( $n$ in column three) are in the top of Panel (a), along with the average ask and bid indicative quotes (in pence/therm), and the corresponding midquotes (columns four, five and six). Standard errors are in brackets. The first $\left(M_{25}\right)$ and third $\left(M_{75}\right)$ interquartile of the midquotes are in column seven and eight, respectively. The distribution of the midquote returns, after being multiplied by $10^{2}$, is summarized in the bottom of Panel (a). Midquote returns have been obtained from changes in the logarithmic midquotes, i.e. $m_{t}=\ln \left(\frac{M_{t}}{M_{t-1}}\right)$, where $m_{t}$ is the midquote return at time $t=1,2, \ldots, T, M_{t}$ is the midquote in column six, and $T$ is the number of observations in column two. The first four moments are in columns two to five (Mean, S.D., Skewness and Kurtosis). The first lag of the autocorrelation function $\rho_{1}$ is in column six. Columns seven and eight show, respectively, the Ljung-Box statistics (L-B) for the null hypothesis of serial independence and the ARCH test for the null hypothesis of homoscedasticity at the $50^{\text {th }}$ order of lags. This order accounts for a time window spanning from 4 hours (data resampled at 5-minute frequency) to one week (Monday-Friday, at 60-minute frequency). In Panel (b) of Table 1 . the descriptive statistics of the trading variables (top) and the distribution of transaction price returns (bottom) are shown. Number of observations and observations per day are in columns two and three, respectively. The average volume (1,000 therm/day), trading size (million $£$ ) and transaction price (pence/therm) observed in each interval are shown in columns three to five along with their standard 
Figure 2: NBP transaction price and midquote series at 60-minute frequency
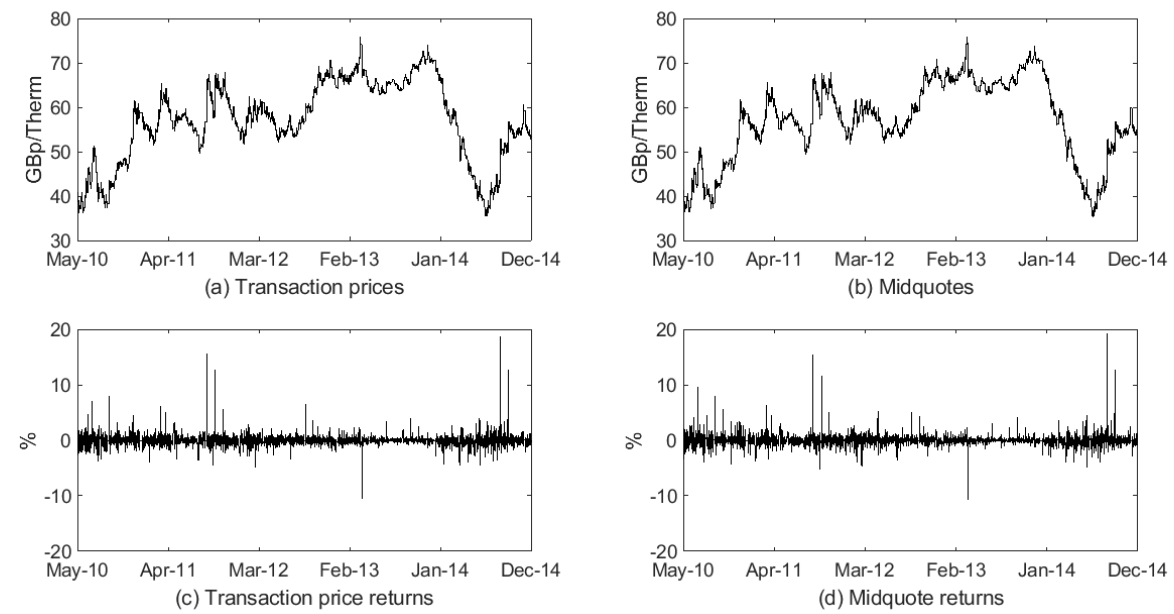

errors (in brackets). The first $\left(P_{25}\right)$ and third $\left(P_{75}\right)$ interquartile of the price series are in columns seven and eight. The first four moments of the price returns pre-multiplied by $10^{2}$ are in columns two to five. The first-order autocorrelation function, the Ljung-Box statistics and the ARCH tests are in columns six to eight. Price returns have been obtained from changes in the logarithmic transaction prices, i.e. $r_{t}=\ln \left(\frac{P_{t}}{P_{t-1}}\right)$, where $r_{t}$ is the price return at time $t=1,2, \ldots, T, P_{t}$ is the transaction price and $T$ is the number of observations.

Resampled midquote and price return series show high skewness and kurtosis, which however reduce with the resampling frequency. That is, higher skewness and kurtosis are observed in the data resampled at 5-minute frequency (21.14 and 2,176 of midquote returns, respectively; 18.85 and 1,873 of price returns), when 121 observations per day are recorded, compared to the data resampled at 60-minute frequency and 11 daily observations (5.851 and 174.7 of midquote returns; 5.412 and 160.2 of price returns). ARCH effects are rejected at $1 \%$ significance level, while serial-correlations appears to be significant mainly at lower frequencies (30 and 60 minutes). Therefore, the focus of subsequent analysis is on 60-minute resampling, because this frequency minimizes leptokurtosis and asymmetric effects and leads to a sample of size $T=11,638$ observations, or 1,058 trading days and 11 observations per day.

The NBP transaction prices and midquotes at 60-minute frequency are depicted in Figure 2 A doubling of prices and midquotes (Figure2, (a)-(b)) is observed between May 2010 and December 2013, and a significant drop is noticeable since January 2014. The increase is more pronounced in the period from the second-half of 2012 to the first-quarter of 2013, and may be linked to natural gas demand-supply imbalances in the UK and Continental Europe, a Norwegian supply disruption, low storage levels, and sustained cold weather in the UK, mainly evident in March 2013 (EC, 2013, Timera 2013). Subsequently, the increasing availability of liquified natural gas (LNG) from the international markets and the slump in international coal prices are likely to have contributed to reductions in natural gas demand since the second-half of 2013, thus leading to declining one-month-ahead NBP forward prices. The return series based on the transaction prices and midquotes (Figure2, (c)-(d)) show volatility clustering, excess kurtosis and heteroscedasticity, which are typical of financial time series and thus support our adoption of measures from the financial literature. An increase in the volatility of the return series can be observed during 2014.

The trading activity in the one-month-ahead NBP forward market is summarized in Figure3 The number of transactions in the 60-minute intervals and by day of the week (Monday-Friday) is depicted 


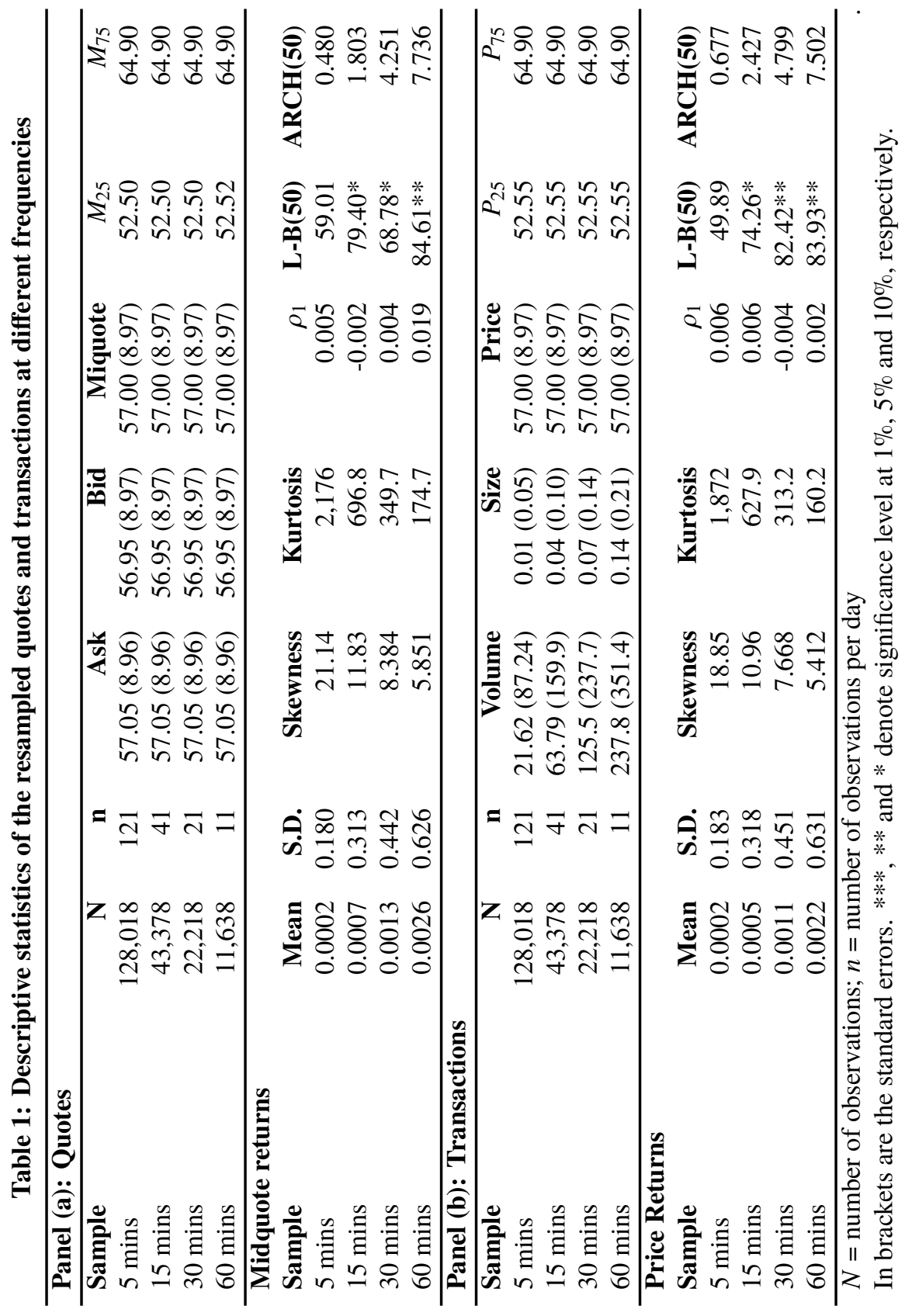




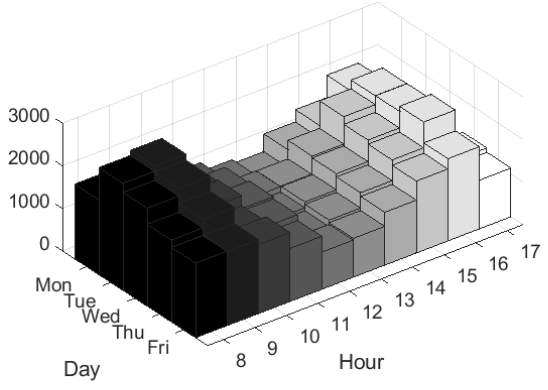

(a) Number of transactions

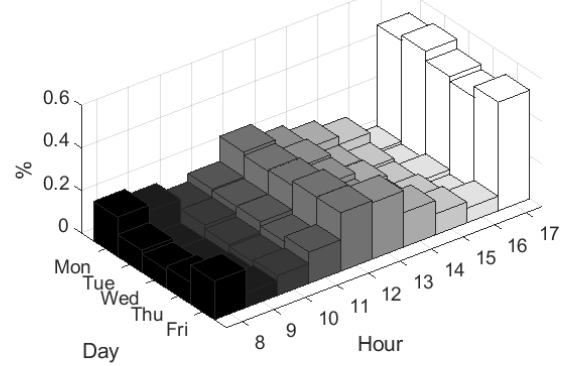

(b) Frequency of no-trading

in chart (a). It is higher when the market opens (8:00-10:00) and in the hour preceding the business day's closure (16:00-17:00). Therefore, the frequency of no-trading, i.e. the number of times where no transactions are recorded in the 60-minute intervals, was considered, by day of the week, and its in percentage was computed (chart (b)). On average, this frequency is $49 \%$ between 16:00 and 17:00, i.e. at the end of the business day. Its value increases to 54\% on Fridays. This finding is in line with financial markets, where lower trading activity is observed at lunchtime and before trading closure (e.g. Covrig and Melvin 2002). Consequently, the subsequent analysis is constrained to the trading window 8:00-16:00, which results in $T=10,580$ observations.

The daily trading activity is shown in Figure 4 The number of transactions per day, over the full sample (chart (a)), indicates decreasing trading activity since May 2013. A seasonal pattern is also observed: transactions per day are greater from September to November and during the winter (January to March), and are likely to reflect weather-dependencies in the natural gas demand. Figure 4 chart (d) shows the daily trading volume (in 1,000 Therm/day) and its variance, which increase, most noticeably from May 2013 onwards. Together, charts (a) and (b) indicate increasing physical trade size, which is likely to be driven by changes in trading behavior and market composition. As predicted by market microstructure theory, both trading activity and return volatility appear to contribute to liquidity. Given the trends and seasonalities observed, the time-varying behavior of liquidity in the period is analyzed in the next section.

\section{RESULTS}

\subsection{Evolution of Measures of Spread in the One-month-ahead NBP Forward Market}

\subsubsection{On the distribution of the measures of spread in the one-month-ahead NBP forward market}

Descriptive statistics of the daily average percentage effective half-spread (Eq1), measuring the one-month-ahead NBP market tightness, are presented in Table 2, along with the inventory and informational components of this spread (Eq2 and Eq 3). Daily averages were computed as timeweighted average of the intraday measures, through multiplying each intraday measure by the relative time it was observed during the day. For each measure, mean, standard deviation (S.D.), lower quartile $\left(Q_{25}\right)$, median, upper quartile $\left(Q_{75}\right)$ and skewness from the empirical distributions are shown in columns two to seven. The first-order autocorrelation coefficient is in column eight. The number of 
Figure 4: Daily Trading activity

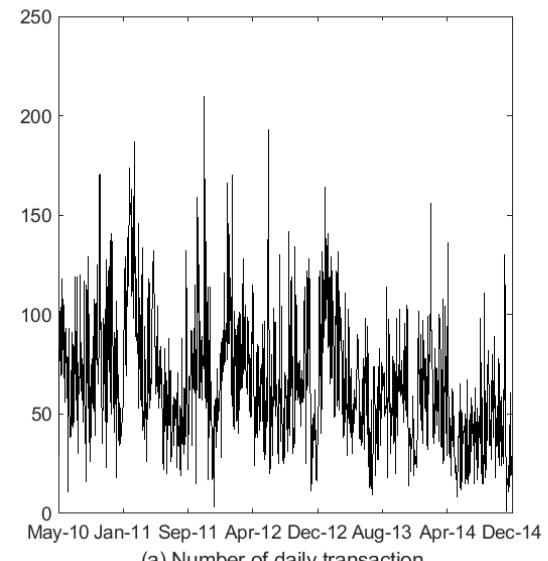

(a) Number of daily transaction

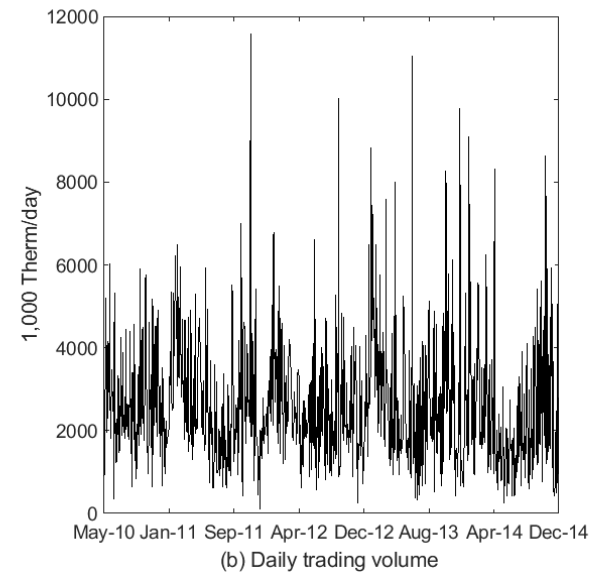

(b) Daily trading volume

Table 2: Descriptive statistics of the daily measures of spread

\begin{tabular}{lcccccccc}
\hline Measure & Mean & S.D. & $Q^{25}$ & Median & $Q^{75}$ & Skewness & $\rho_{1}$ & $\mathbf{N}$ \\
\hline$E H S$ & 0.311 & 0.222 & 0.164 & 0.243 & 0.388 & 2.056 & $0.589^{* * *}$ & 1,058 \\
$R H S$ & 0.171 & 0.185 & 0.064 & 0.129 & 0.241 & 2.300 & $0.378^{* *}$ & 1,058 \\
$P I$ & 0.140 & 0.146 & 0.062 & 0.113 & 0.184 & 1.737 & $0.258^{* *}$ & 1,058 \\
\hline
\end{tabular}

$N=$ number of observations.

$* * *, * *$ and $*$ denote significance level at $1 \%, 5 \%$ and $10 \%$, respectively.

observations $(N)$ is in the last column. The distributions are asymmetric and positively autocorrelated. On average, daily transaction costs in the one-month-ahead NBP forward market are $0.311 \%$ and split between a transitory and non-informational component of $0.171 \%$, given by the measure of spread $R H S$, and a permanent and informational component of $0.140 \%$, given by the measure $P I$. That is, on average, inventory costs represent $55 \%(0.171 / 0.311)$ of the transaction costs, the remaining $45 \%$ is due to asymmetric information. The t-test statistic for comparing the means of the measures RHS and PI is significant at 5\% significance level. Similarly, non-parametric sign test statistics for the equality between the respective medians and interquartiles are significant at 5\% level. Consequently, there are differences between the distributions of inventory and informational costs, thus implying distinct behaviors of the different components of the transaction costs in the one-month-ahead NBP forward market.

The deseasonalization described in Section 3.3 is summarized in Table 3, It can be observed that the measures of spread tend to be higher from April to October and lower from November to March, thus implying greater transaction costs and lower liquidity in the summer than in the winter. This seasonal behavior of the measures tallies with the previous observation on monthly behavior in Fig 3 , thus further highlighting the weather-dependent seasonal component of liquidity in the one-month-ahead NBP forward market that resembles the observed pattern of trading activity. Furthermore, the measures of spread are higher on Mondays relative to other trading days. Finally, a significant negative trend is found in the time series, thus implying that the transaction costs decrease in the period.

\subsubsection{On the distribution of seasonally adjusted measures of spread}

Descriptive statistics of the seasonally adjusted daily measures of spread are presented in Table 4 Higher asymmetry is observed in the distributions of the measures of spread relative to their 


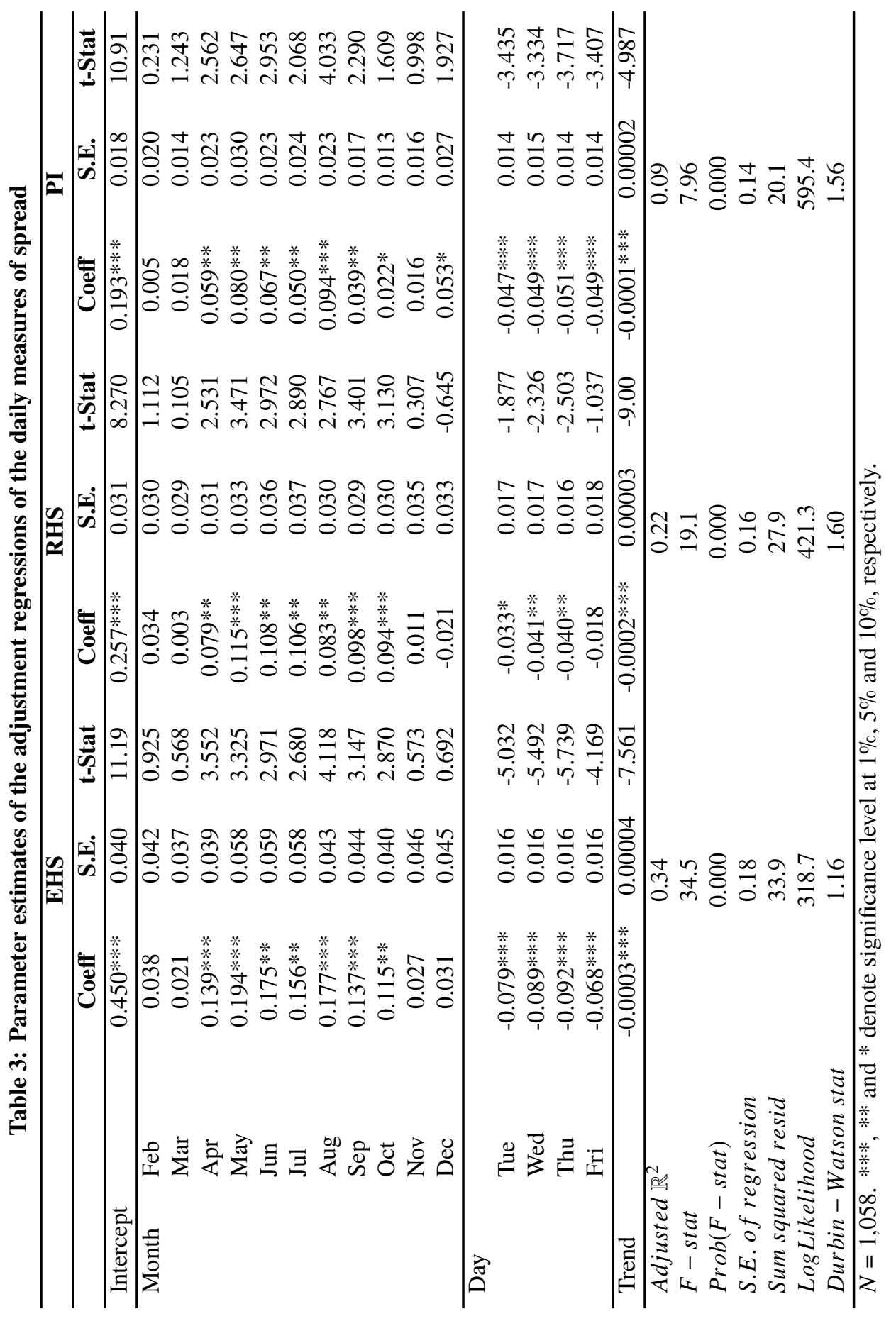


Table 4: Descriptive statistics of the seasonally adjusted daily measures of spread

\begin{tabular}{|c|c|c|c|c|c|c|c|}
\hline Measure & Mean & S.D. & $Q^{25}$ & Median & $Q^{75}$ & Skewness & $\rho_{1}$ \\
\hline$E H S$ & 0.311 & 0.222 & 0.173 & 0.262 & 0.393 & 3.089 & $0.397 * * *$ \\
\hline$R H S$ & 0.171 & 0.185 & 0.078 & 0.145 & 0.237 & 3.236 & $0.156^{* * *}$ \\
\hline$P I$ & 0.140 & 0.146 & 0.059 & 0.112 & 0.196 & 1.895 & $0.189 * * *$ \\
\hline
\end{tabular}

non-adjusted series, as implied by their skewness (seven). This is mainly evident when considering the effective spread $E H S$ and its inventory component $R H S$.

Monthly median values of the unadjusted and seasonally adjusted measures of spread are reported in Figure 5. Overall, compared to the unadjusted measures, the adjusted measures of spread unveil an increase in transaction costs in the one-month-ahead NBP forward market during 2014 (charts (d)-(f)). Furthermore, the adjusted measures are higher during the winter, especially when considering the effective spread $(E H S)$ and its inventory component $(R H S)$, and appear to be more volatile in 2014 than in previous years.

Parameter estimates of the adjustment regressions of the daily trading volume and number of transactions are presented in Table 5. Monthly effects are significant and imply lower and more volatile trading activity in the summer. Trading appears to be lower on Mondays relative to rest of the week, that is when the measures of spread are higher (Table 3). Finally, a significant and negative trend is found in the daily volume and number of transactions, thus tallying with the evidence from the measures of spread.

The seasonally adjusted series of the daily number of transactions and trading volume are shown in Figure 6 Data are displayed by year and by month. Especially in 2014, the series highlight a reduction in trading activity, that is when an increase in the measures of spread is observed, and thus the transaction costs are higher, as highlighted above.

\subsubsection{On the association between measures of spread and trading activity}

Table 6 presents the Spearman's rank correlation coefficients between changes in the seasonally adjusted measures of spread and trading activity. The non-parametric Spearman's rank coefficient has been used since it allows for possible non-linear dependencies between variables, while minimizing the effect of extreme values (Gibbons and Chakraborti, 2003). Correlation is high and positive between changes in the effective spread $(E H S)$ and its inventory component $R H S(0.533)$, and between changes in the effective spread and its informational component $P I(0.421)$; correlation is negative between changes in the inventory component and informational component (-0.394). Furthermore, the correlation is positive between changes in the inventory component and number of transactions and trading volumes ( 0.107 and 0.135$)$, and negative between changes in the informational component and number of transactions and trading volumes (-0.113 and -0.114).

Overall, the distributions of the individual measures of spread and their dynamics suggest seasonality and decreasing transaction costs in the period analyzed, and imply improvements in market tightness. Nonetheless, the bivariate correlations indicate that the two components of the effective spread, which represent the inventory costs and the asymmetric-information costs, behave idiosyncratically. Hence, the different transactions costs may have distinct impacts on the one-month-ahead NBP forward market tightness, depending upon their relative contributions to the effective spread, and have implications when considering the pressure exerted by trading activity on prices.

\subsection{Interpreting the Relative Contribution of the Transaction Costs}

Parameter estimates of three way-decomposition model defined by Eq 5 6 are reported in Table 7 The estimated constant spread amounts to $0.237 \%$ throughout the period $(\gamma)$; asymmetric-information costs 


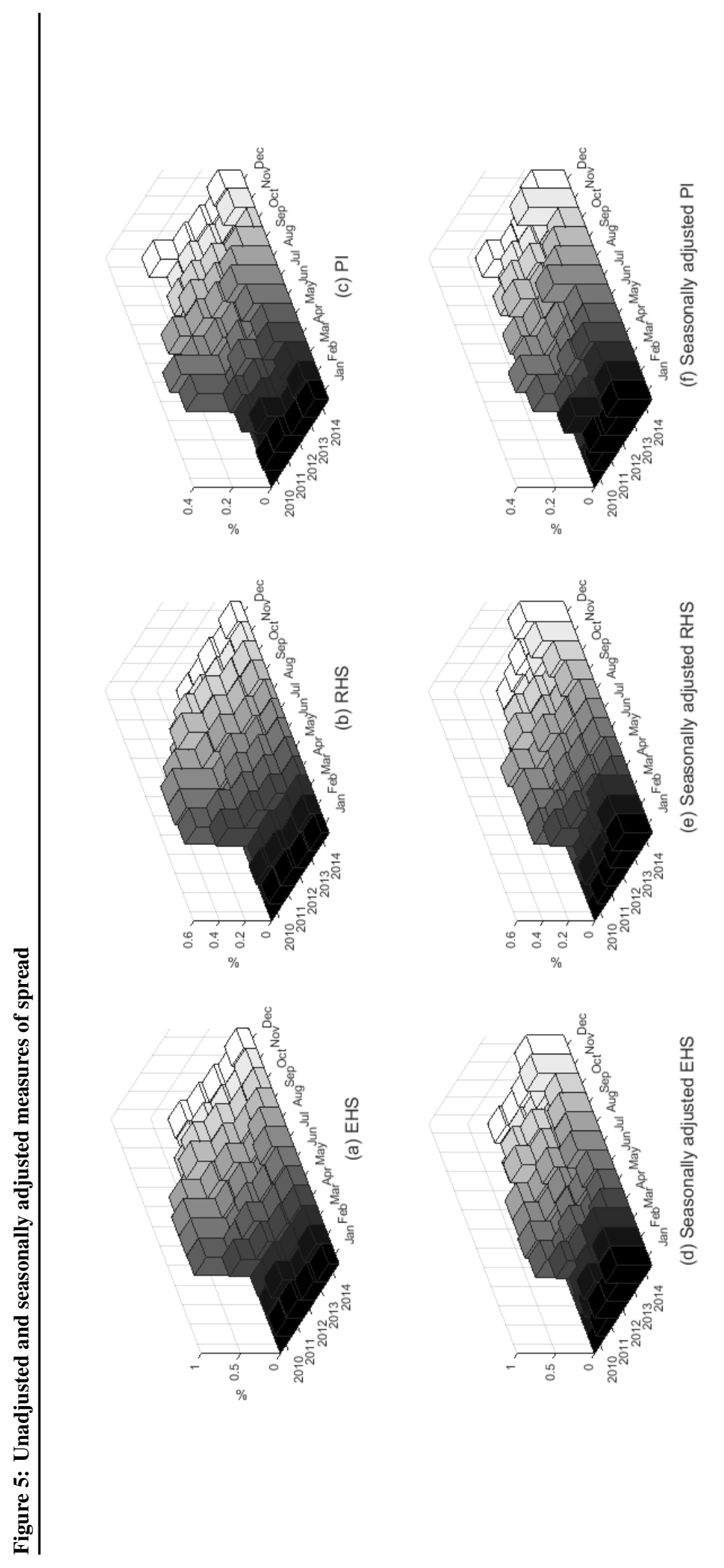

Copyright (C) 2016 by the IAEE. All rights reserved. 
Table 5: Parameter estimates of the adjustment regressions of the daily trading activity

\begin{tabular}{|c|c|c|c|c|c|c|c|}
\hline & \multicolumn{3}{|c|}{ Trading volume } & \multicolumn{3}{|c|}{ Number of transactions } \\
\hline & & Coeff & S.E. & t-Stat & Coeff & S.E. & t-Stat \\
\hline \multicolumn{2}{|l|}{ Intercept } & $8.031 * * *$ & 0.800 & 10.039 & $4.648 * * *$ & 0.660 & 7.042 \\
\hline \multirow[t]{11}{*}{ Month } & Feb & 0.065 & 0.090 & 0.726 & $0.122 *$ & 0.067 & 1.809 \\
\hline & Mar & -0.147 & 0.094 & -1.564 & $-0.161 * * *$ & 0.084 & -1.912 \\
\hline & Apr & $-0.283 * * *$ & 0.088 & -3.211 & $-0.231 * * *$ & 0.065 & -3.545 \\
\hline & May & $-0.399 * * *$ & 0.103 & -3.888 & $-0.380 * * *$ & 0.072 & -5.314 \\
\hline & Jun & $-0.530 * * *$ & 0.101 & -5.236 & $-0.577 * * *$ & 0.084 & -6.907 \\
\hline & Jul & $-0.593 * * *$ & 0.095 & -6.231 & $-0.570 * * *$ & 0.076 & -7.516 \\
\hline & Aug & $-0.469 * * *$ & 0.097 & -4.821 & $-0.543 * * *$ & 0.079 & -6.915 \\
\hline & Sep & $-0.324 * * *$ & 0.095 & -3.420 & $-0.375 * * *$ & 0.077 & -4.861 \\
\hline & Oct & $-0.175^{*}$ & 0.092 & -1.890 & $-0.235 * * *$ & 0.069 & -3.396 \\
\hline & Nov & -0.079 & 0.092 & -0.866 & $-0.168 * *$ & 0.077 & -2.171 \\
\hline & Dec & $-0.726 * * *$ & 0.114 & -6.367 & $-0.847 * * *$ & 0.102 & -8.340 \\
\hline \multicolumn{8}{|l|}{ Day } \\
\hline & Tue & $0.265 * * *$ & 0.044 & 6.014 & $0.169 * * *$ & 0.035 & 4.806 \\
\hline & Wed & $0.195 * * *$ & 0.048 & 4.073 & $0.100 * *$ & 0.045 & 2.229 \\
\hline & Thu & $0.207 * * *$ & 0.048 & 4.307 & $0.119^{* *}$ & 0.040 & 2.941 \\
\hline & Fri & $0.089^{*}$ & 0.050 & 1.792 & 0.027 & 0.039 & 0.699 \\
\hline Trend & & $-0.0003^{* * *}$ & 0.00006 & -4.490 & $-0.0006 * * *$ & 0.00006 & -10.785 \\
\hline \multicolumn{2}{|c|}{$\overline{\text { Adjusted } \mathbb{R}^{2}}$} & & 0.20 & & & 0.35 & \\
\hline \multicolumn{2}{|c|}{$F-s t a t$} & & 17.7 & & & 36.2 & \\
\hline \multicolumn{2}{|c|}{$\operatorname{Prob}(F-s t a t)$} & & 0.000 & & & 0.000 & \\
\hline \multicolumn{2}{|c|}{ S.E. of regression } & & 0.51 & & & 0.43 & \\
\hline \multicolumn{2}{|c|}{ Sum squared resid } & & 271.1 & & & 195.4 & \\
\hline \multicolumn{2}{|c|}{ LogLikelihood } & & -780.9 & & & -607.6 & \\
\hline \multicolumn{2}{|c|}{ Durbin - Watson stat } & & 1.70 & & & 1.66 & \\
\hline
\end{tabular}

represent $14.7 \%$ of the spread $(\alpha)$; inventory costs account for $50.5 \%(\beta)$ while the order-processing costs contribution $(1-\alpha-\beta)$ is $34.8 \%$. Coefficients are significantly different from zero and imply that inventory costs represent the largest component in transaction costs. A the Wald test for the null hypothesis of $\beta$ greater than $\alpha$ is not rejected ( $p$-value 0.0364 ) thus supporting the findings in Table 4 Results in Table 7 also highlight positive autocorrelation in the order flow $(\varphi=0.269)$. Notwithstanding inventory effects should lead to negatively autocorrelated orders, a positive serial correlation is consistent with the expectation that investors tend to split large-size orders, which requires correspondingly large inventory levels, by executing them in different sequential orders at a single price to reduce price impact. As argued by Huang and Stoll (1997), when the estimated autocorrelation is lower than 0.5 , the the impact of asymmetric-information costs is attenuated, and the adjustment of prices ascribed to the inventory costs is increased. Consequently, the estimated coefficient $\varphi$ can be an upper bound for the autocorrelation in order flow Huang and Stoll (1997). In all, the results of the three way-decomposition model highlight the importance of inventory costs in the one-month-ahead NBP forward market.

\subsection{Assessing the impact of trading activity on prices}

The measure of price impact $\lambda_{n}$ in Eq 6is estimated over 60-minute intervals to assess the pressure exerted by traded-volume imbalances on the one-month-ahead NBP forward prices. Parameter estimates of the adjustment regressions accounting for seasonalities and trends in the returns and 

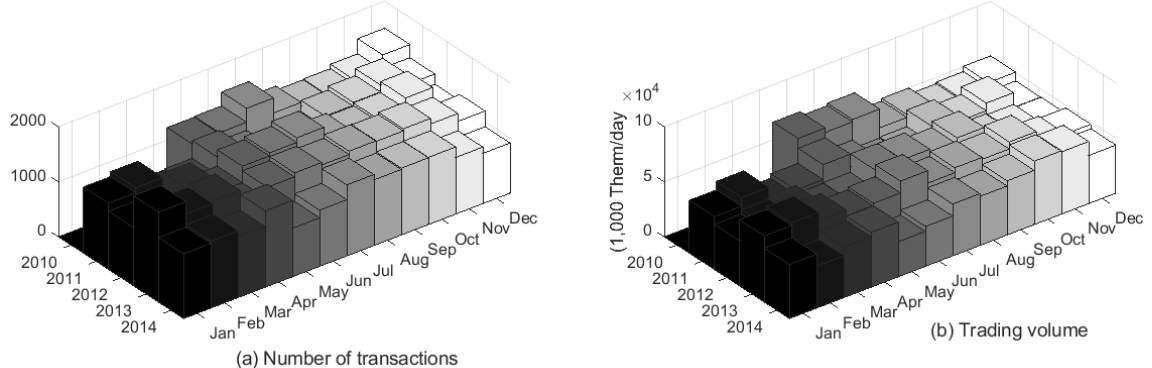

Table 6: Association between changes in the measures of spread and trading activity: Spearman's rank correlation coefficients

\begin{tabular}{lccccc}
\hline & $E H S$ & $R H S$ & $P I$ & No. of Trans. & Trading Volume \\
\hline$E H S$ & 1 & & & & \\
$R H S$ & $0.533^{* * *}$ & 1 & & & \\
$P I$ & $0.421^{* * *}$ & $-0.394^{* * *}$ & 1 & & \\
No. of Trans. & -0.003 & $0.107^{* * *}$ & $-0.113^{* * *}$ & 1 & 1 \\
Trading Volume & 0.031 & $0.135^{* * *}$ & $-0.114^{* * *}$ & $0.729^{* * *}$ & 1 \\
\hline$N=1,058 . * * *, * *$ & and $*$ denote significance level at $1 \%, 5 \%$ and $10 \%$, respectively.
\end{tabular}

traded-volume imbalances series are presented in Table 8 and illustrate the intraday patterns. Both the series are stationary and tend to be higher in the morning and lunchtime, thus suggesting a positive association between the two series. Seasonally adjusted returns and traded-volume imbalances are used to estimate the time-varying measure of price impact $\lambda_{n}$, which is shown in Figure 7 , chart (a). Confidence intervals, based on Newey-West robust standard errors, are reported in the figure. The measure indicates a positive correlation between returns and imbalances, which gradually decreases over the period up to March 2014. This correlation increases and becomes more volatile in the subsequent period.

When compared with the cumulative traded-volume imbalances over the rolling windows ( $\operatorname{chart}(\mathrm{b})$ ), a negative correlation between price impact and traded-volumes imbalances can be inferred. That is, the decrease in the price impact tallies with increasing and positive traded-volume imbalances, which denote greater buyer-initiated traded-volumes relative to the seller-initiated and are mainly evident up to July 2013. Conversely, an increase in price impact occurs during 2014, when these imbalances reduce and higher transaction costs are also observed in the market (Figure 5.

\section{DISCUSSION}

Drawing from the financial market microstructure literature, this study was designed to capture tightness, depth and resilience of the one-month-ahead NBP forward market from May 2010 to December 2014, thus making a comprehensive assessment of its liquidity in the period. As a whole, measures of spread showed an improvement in market tightness, since a negative trend was observed in the period. Considering the daily percentage effective half-spread, market tightness was on average $0.31 \%$, which given its standard deviation reported in Table 4 is consistent with the regulator's estimate in the same period $(0.22 \%$, based on bid-ask spread, Ofgem (2016)). However, the bid-ask spread, as highlighted above, is mainly associated with inventory costs (Roll, 1984, Stoll, 1989) and can understate transaction costs in OTC markets, where the bid and ask quotes are non-binding 
Table 7: Parameter estimates of three way-decomposition of the spread

\begin{tabular}{llll}
\hline & Coeff & S.E. & t-Stat \\
\hline$\gamma$ & $0.237^{* * *}$ & 0.007 & 34.06 \\
$\alpha$ & $0.147^{*}$ & 0.086 & 1.703 \\
$\beta$ & $0.505^{* * *}$ & 0.087 & 5.820 \\
$\varphi$ & $0.269^{* * *}$ & 0.037 & 7.248 \\
\hline Adjusted $\mathbb{R}^{2}$ & & 0.13 & \\
S.E. of regression & & 0.59 & \\
Durbin - Watson stat & & 1.98 & \\
\hline$N=1,058$.
\end{tabular}

$N=1,058$.

$* * *, * *$ and $*$ denote significance level at $1 \%, 5 \%$ and $10 \%$, respectively.

Table 8: Parameter estimates of the adjustment regressions of the returns and traded-volume imbalances

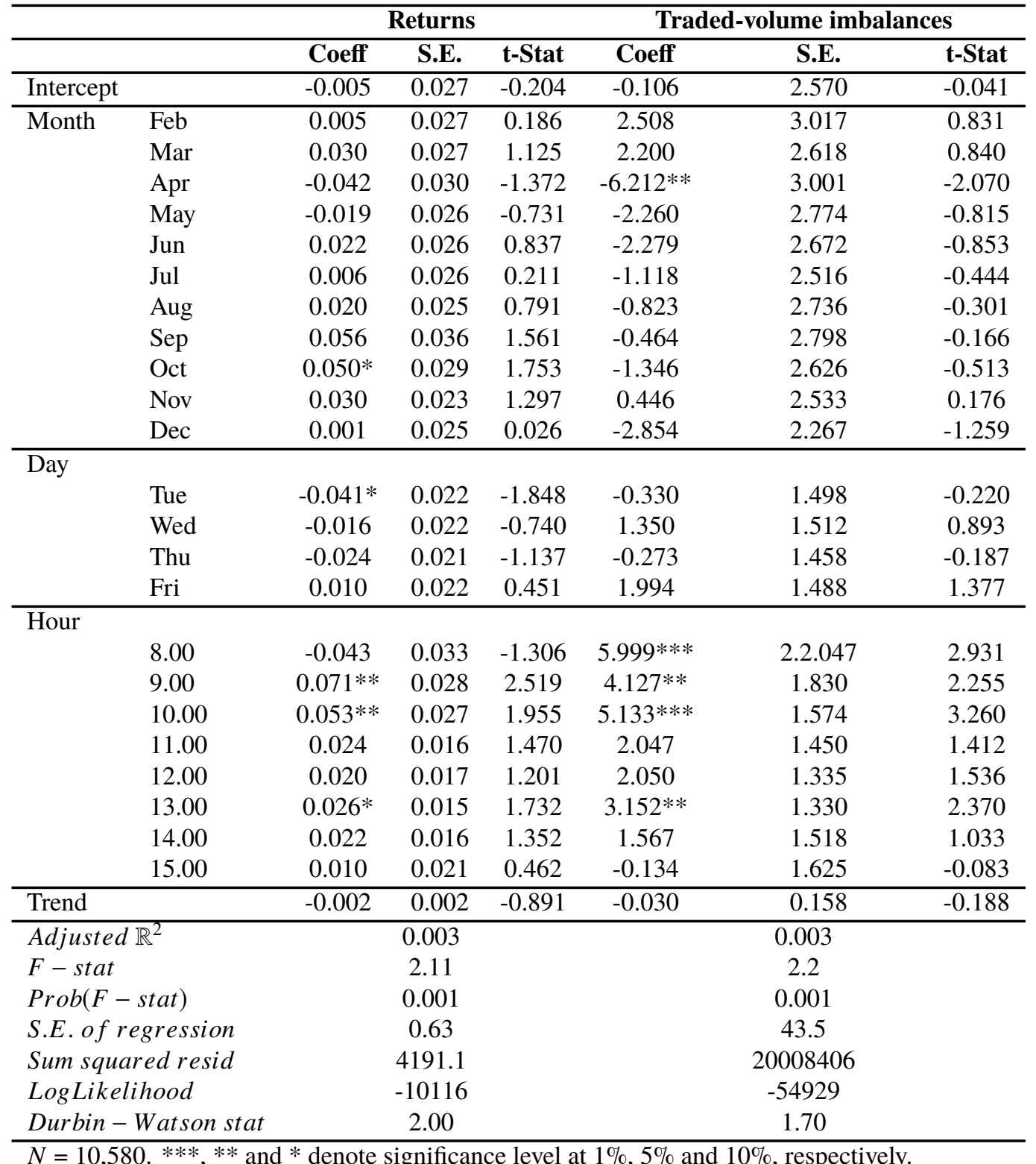


Figure 7: Time-varying measure of price impact $\lambda_{n}$ and traded-volume imbalances over the rolling windows $^{a}$

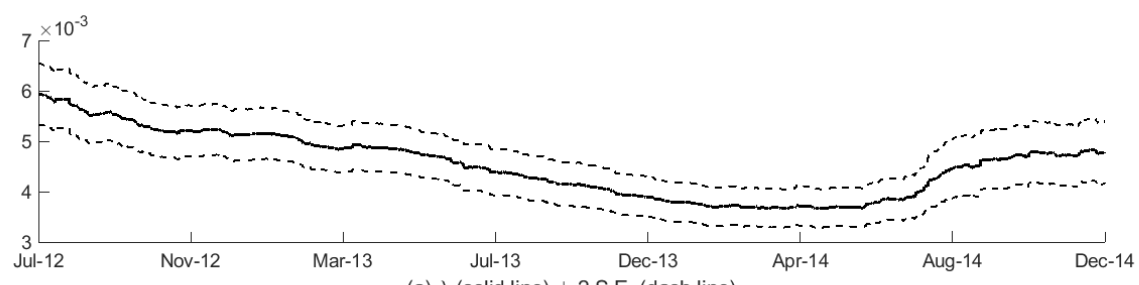

(a) $\lambda$ (solid line) \pm 2 S.E. (dash line)

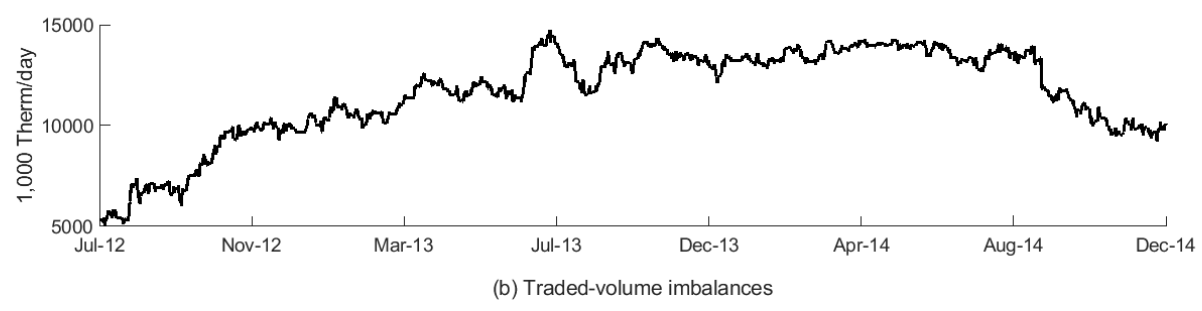

${ }^{a}$ Rolling windows of size $m=5,000$ have been considered over the sample $T=10,580$, leading to $N=5,581$ estimates of the measure.

and based on the inter-dealers' trading orders and expressions of interest. Furthermore, the bid-ask spread does not permit assessments of the different components in transaction costs (order processing, inventory and asymmetric information), nor inferences on the depth and resilience of the market.

According to the measures of spread in this study, inventory costs and asymmetric-information costs were on average $0.171 \%$ and $0.140 \%$ in the period ( $R H S$ and PI in Table 4, respectively). The inventory costs are therefore consistent with the Ofgem's bid-ask spread with $99 \%$ level of confidence, which still only captures one component in transaction costs. In addition, estimates of inventory costs are greater than asymmetric-information costs, thus implying that over $50 \%$ of the one-month-ahead NBP forward market's tightness is due to inventory costs. This finding is supported by the "three-way decomposition" of the spread, which also allows for inferences on the order processing costs. In all, this decomposition suggests that inventory costs and asymmetric-information costs represent 50.5\% and $14.7 \%$ of the transaction costs ( $\alpha$ and $\beta$ in Table 7 , respectively), with the remaining $34.8 \%$ being attributable to order processing costs $(1-\alpha-\beta)$. These results are relevant, since inventory costs reflect the availability of immediate liquidity in the market and have a temporary effect on prices (Stoll, 1978). Moreover, they are important for short-term portfolio re-balancing and dynamic hedging strategies (Dupuis et al., 2016): the higher the inventory costs, the lower the immediate liquidity, the more expensive is to find a counterparty when in need to adjust a position. These findings imply differences in microstructure between one-month-ahead NBP forward market and stock market since, in the latter, inventory costs represent a much lower component of the spread when compared to the asymmetric-information costs, and are thus neglected in transaction cost evaluations Engle and Neri (2010).

Trading activity may induce traded-volumes imbalances in a market, which exert pressure on prices. In this study, this pressure was captured by the time-varying price impact measure $\lambda_{n}$, which allowed for an assessment of the depth and resilience of the one-month-ahead NBP forward market over the period 2010-14. This measure underscored a positive and dynamic correlation between returns and traded-volume imbalances, which has been also observed in financial markets (e.g. Payne, 2003) and cannot be inferred from measures of spread. A decreasing price impact was observed in the period 2010-13, and this decrease was coupled with increasing and positive traded-volume imbalances. These imbalances imply higher buyer- than seller-initiated traded volumes, in other words buying pressure. In short, high market depth is observed in this period. Price impact increased in 2014, tallying with reducing traded-volume imbalances and implying lower depth in the market at the time. 
These observations confirm that market liquidity is dynamic. Moreover, response to shocks vary in the period studied and thus, in assessing price impact, a time-varying approach is needed in order to capture changes.

During 2010-13, an annual 5\% drop was observed in the European Union natural gas demand compared to the 2010 level (Source: Eurostat, http://ec.europa.eu/eurostat/data/database). In parallel, a wave of liquefied natural gas (LNG) moved towards the UK, in particular during 2010-12 (Heather 2015). The oversupply of natural gas in the European market and the consequent premium of oil-linked contracts over hub prices in Continental Europe became an incentive to buy from hubs, in anticipation of higher hub prices driven by increasing crude oil price during the period. These circumstances may explain the decrease in $\lambda_{n}$ and the simultaneous increase in buying pressure during 2010-13, and are consistent with comments by Hartley (2015). During 2013-14, NBP saw a drop in physical deliveries, in favor of the TTF hub (EC, 2015), and a progressive shift of trades from the OTC to the exchange-trade venue. The drop in the NBP prices during 2014 (Figure 2), has been attributed to the steady decline in international coal prices and the increase in the flow of LNG to Europe, and may have added pressure to the market, thus explaining the high price impact in a time of low traded-volume imbalances. This interpretation would be consistent with the decreasing number of transactions and the simultaneous growth in the traded volumes (Figure 4), and with higher effective spread and inventory costs (Figure 5, chart (d)-(e)) at that time, thus denoting lower liquidity and a positive link between effective spread and price impact in the market. In summary, while the spread informs about the costs of each transaction, the price impact $\lambda_{n}$ reveals the cost of trading large volumes in a given time-interval. This latter cost plays a key role in forward trading and exhibits dynamics that are likely to reflect market conditions.

Overall, the findings have implications for assessments of market quality. Low liquidity constrains intertemporal arbitrage between spot and forward markets and increases the pressure exerted by trading activity on prices, thus limiting the opportunity for trading and the development of gas hubs (Nick, 2016). Low liquidity may also hamper the flexibility of gas storage facilities. Storage represents a real option, because it offers the immediate opportunity to trade natural gas or to wait for better markets conditions, as prescribed by the theory of storage (Fama and French, 1987). Felix et al. (2013) argued that storage operators anticipate market liquidity and take this expectation into account in their operating decisions: the lower liquidity, the higher the market price, the lower is the storage value. Yet, depending upon the market's depth and resilience, and the relative importance of each individual component of the transaction costs, liquidity constraints may have a short- or long-lasting impacts on a market: while asymmetric-information costs have a permanent impact on liquidity, inventory costs are more likely to reflect short-term adjustments in the market and reduce liquidity temporarily. These dynamics are unrecoverable from the churn ratio, which only captures the combined fluctuations of traded-volumes and physical deliveries, and does not allow to discriminate between them, nor to make inferences about their impacts on prices.

The analysis carried out in this study captures the dynamics of the market liquidity, after removing the deterministic components of the time series. The importance of deseasonalizing and detrending the time series can be inferred from a comparison of unadjusted and seasonally adjusted measures of spread in Figure 5. The unadjusted measures suggest a relatively greater role of asymmetric-information costs ( $R H S$ in chart (b)) compared to the inventory costs (PI, chart (c)), while they appear to understate transaction costs in the market, in particular during 2013-14. Hence, this study contributes towards a better understanding of the evolution of liquidity in the one-month-ahead NBP forward market. As highlighted by Geman (2007), the properties of the natural gas price series may have changed from mean-reverting to random walk since 2000-01. Non-stationarity has been observed in natural gas price series (e.g. Nick, 2016; Asche et al. 2017), thus supporting the adoption of financial market microstructure theory and measures to assess liquidity in energy markets. However, in contrast to financial markets, natural gas markets are characterized by seasonalities, which can affect liquidity, as illustrated in this study. 


\section{CONCLUSIONS}

This article extended the perspective of financial market microstructure to investigate liquidity in natural gas markets, more specifically in the one-month-ahead NBP forward market. Measures of spread, the "three-way decomposition" regression model and the modified time-varying price impact measure were used to assess market tightness, depth and resilience. The key properties of market liquidity were evaluated, and the usefulness of measures and methods from financial markets was illustrated in an energy market context. The findings implied a relative greater contribution of inventory costs to tightness in the one-month-ahead NBP forward market, and thus have implications for NBP forward trading as well as operational decisions concerning physical assets (e.g. storage facilities) in the interconnected European gas (energy) markets.

The three-way decomposition and the measure of price impact helped in linking returns to trading activity. In particular, measuring price impact allowed for assessments of how price reacted to trading activity in the period studied, thus providing insights into the cost of quickly trading large volumes in the market. This knowledge plays a key role in facilitating risk sharing and portfolio rebalancing, and is unrecoverable from the measures of spread, which can only enable the assessment of the cost of individual transactions. Furthermore, the measure of price impact was shown to be more informative than the churn ratio, which is traditionally used when assessing liquidity in energy markets but does not consider the impact of trading activity on prices. Therefore, the measure of price impact in this study can be valuable to investors in natural gas markets, who are risk-averse and concerned about liquidity as an instrument to stabilize price fluctuations. Since liquidity implies the ability to trade promptly and in reasonable amounts at prices that properly reflect current market conditions, this measure can provide insights towards investment decisions at shorter horizons, when investors are more concerned about trading costs and price returns contain information on any risk premium reflecting market liquidity. Given the complexities of balancing natural gas demand and supply, this information is of interest to market players valuing high flexibility in the way they can buy and sell the commodity, and cannot be recovered from measures of spread or from the churn ratio.

In all, tightness, depth and resilience reflect liquidity, and are also properties of energy markets. They describe the extent to which a market may offer sufficient opportunities for trading at a manageable cost and with a credible price. Low liquidity may impede trading, thereby making it easier for a single player to assume a dominant position, with implications for price fluctuations and volatility. In this respect, the observed increase in market tightness during 2014, which was coupled with low depth and resilience, decreasing numbers of transactions and higher variability in average volumes, may have signaled high market concentration in the one-month-ahead NBP forward market at the time. Under such conditions, the participation of the smaller energy companies in the NBP trading could be threatened, with possible consequences for competitiveness, investment decisions and, overall, market efficiency of NBP and related markets. Therefore, the measure of price impact in this study can become valuable to policymakers and regulators when monitoring market quality.

Notwithstanding the contribution of this study, there are limitations to be considered. The assessments are restricted to the share of the market, contracts and period examined. Nonetheless, the market microstructure perspective adopted also allows for comparisons of liquidity across markets, venues and different contract maturities. It can be further explored in future research and practice. With greater availability of data following the implementation of EU Directives on market transparency, implications of recent political decisions, changes in the regulatory environment and, more broadly, energy trading can be investigated, and provide additional insights into the evolving European energy markets.

Copyright (c) 2016 by the IAEE. All rights reserved. 


\section{ACKNOWLEDGEMENTS}

The authors are grateful to Tullett Prebon Information, in particular to Abigail Lee and Matt Joy, for making the data available to this study. We wish to thank the Editors and three anonymous referees for helpful suggestions and comments. Marianna Russo also acknowledges funding from Cass Business School and Science Foundation Ireland, Grant No. 09/SRC/E1780. All errors remain our own.

\section{REFERENCES}

Amihud, Y. (2002). "Illiquidity and stock returns: cross-section and time series effects." Journal of Financial Markets, 5(1): 31-56.

Amihud, Y. and H. Mendelson (1980). "Dealership market: Market-making with inventory." Journal of Financial Economics, 8(1): 31-53.

Amihud, Y. and H. Mendelson (1986). “Asset pricing and the bid-ask spread.” Journal of Financial Economics, 17(2): 223-249.

Asche, F., A. Oglend and P. Osmundsen (2017). "Modeling UK natural gas prices when gas prices periodically decouple from the oil price." The Energy Journal, 38(2): 131-148.

Bagehot, W. [pseud.] (1971). "The only game in town." Financial Analysts Journal, 27(2): 12-14.

Banti, C., K. Phylaktis and L. Sarno (2012). "Global liquidity risk in the foreign exchange market." Journal of International Money and Finance, 31(2): 267-291.

Barndorff-Nielsen, O. E., P. R. Hansen, A. Lunde and N. Shephard (2009). "Realised kernels in practice: Trades and quotes." Econometrics Journal, 12(3): C1-C33.

Bessembinder, H. (2003). "Issues in assessing trade execution costs." Journal of Financial Markets, 6(3): 233-257.

Bessembinder, H. and K. Venkataraman (2010). “Bid-Ask spreads: Measuring trade execution costs in financial markets.” In: Encyclopedia of Quantitative Finance, Rama Cont (Eds.), John Wiley \& Sons Ldt, p. 184-190.

Bevin-McCrimmon, F., I. Diaz-Rainey and G. Sise (2016). "Liquidity and risk premia in electricity futures." USAEE Working Paper No. 16-291. Retrived from https://papers.ssrn.com/sol3/papers.cfm?abstract_id=2885453

Boffelli, S. and G. Urga (2015). "Macroannouncements, bond auctions and rating actions in the European Government bond spreads." Journal of International Money and Finance, 53(May 2015): 148-173.

Brennan, M. J. and A. Subrahmanyam (1996). "Market microstructure and asset pricing: On the compensation for illiquidity in stock returns." Journal of Financial Economics, 41(3): 441-464.

Brownlees, C. T. and G. M. Gallo (2006). "Financial econometric analysis at ultra-high frequency: Data handling concerns." Computational Statistics and Data Analysis, 51(4): 2232-2245.

Choi, J. Y., D. Salandro and K. Shastri (1988). “On the estimation of bid-ask spreads: Theory and evidence.” Journal of Financial and Quantitative Analysis, 23(2): 219-230.

Chordia, T., R. Roll and A. Subrahmanyam (2000). "Commonality in liquidity." Journal of Financial Economics, 56(1): 3-28.

Chordia, T., A. Sarkar and A. Subrahmanyam (2005). "The joint dynamics of liquidity, returns, and volatility across small and large firms." Finance. UCLA: Finance, Retrived from http://escholarship.org/uc/item/6z81z2wc

Covrig, V. and M. Melvin (2002). "Asymmetric information and price discovery in the FX market: Does Tokyo know more about the yen?" Journal of Empirical Finance, 9(3): 271-285.

Cummins, M. and B. Murphy (2015). "Natural gas markets and products.” In: Handbook of Multi-Commodity Markets and Products, Andrea Roncoroni, Gianluca Fusai, Mark Cummins (Eds.), John Wiley \& Sons Ldt, p. 135-180.

Demsetz, H. (1968). “The cost of transacting." Quarterly Journal of Economics, 82(1): 33-53.

Dupuis, D. J., G. Gauthier and F. Godin (2016). "Short-term hedging for an electricity retailer." The Energy Journal, 37(2): 31-59.

Easley, D. and M. O'Hara (1987). "Price, trade size, and information in securities markets." Journal of Financial Economics, 19(1): 69-90.

European Commission. (2013). "Quarterly Report on European Gas Markets.” Volume 6 (Issues 3 \& 4; third and fourth quarter of 2013).

European Commission. (2015). "Quarterly Report on European Gas Markets." Volume 7 (Issue 4; fourth quarter of 2014).

Engle, R. and B. Neri (2010). "The impact of hedging costs on the bid and ask spread in the options market." Unpublished Working Paper, New York University. Retrived from https: //www.researchgate.net/profile/Breno_Neri/publication/228818078_The_Impact_of_Hedging_ Costs_on_the_Bid_and_Ask_Spread_in_the_Options_Market/links/00b495357b1173faed000000/ The-Impact-of-Hedging-Costs-on-the-Bid-and-Ask-Spread-in-the-Options-Market.pdf 
Fama, E. F. (1991). "Efficient capital markets: II.” Journal of Finance, 46(5): 1575-1617.

Fama, E. F. and K. R. French (1987). "Commodity futures prices: Some evidence on forecast power, premiums and the theory of storage" Journal of Business, 60(1): 55-73.

Felix, B., O. Woll, O. and C. Weber (2013). "Gas storage valuation under limited market liquidity: An application in Germany" European Journal of Finance, 19(7-8): 715-733.

Foucault, T., M. Pagano and A. Röell (2013). "Market liquidity.” Oxford University Press.

Frestad, D. (2012). "Liquidity and dirty hedging in the Nordic electricity market." Energy Economics, 34(5): 1341-1355.

Furió, D., J. J. Lucia and V. Meneu (2009). "The Spanish electricity intraday market: Prices and liquidity risk." Current Politics and Economics of Europe, 20(1): 1-22.

Geman, H.(2007). "Mean reversion versus random walk in oil and natural gas prices.” In: Advances in Mathematical Finance, Michael C. Fu, Robert A. Jarrow, Ju-Yi J. Yen, Robert J. Elliott (Eds.), Springer, p. 219-228.

Gibbons, J. D. and S. Chakraborti (2003). “Nonparametric statistical inference.” Marcel Dekker (4th Eds.), Springer.

Glosten, L. R. and L. E. Harris (1988). "Estimating the components of the bid/ask spread." Journal of Financial Economics, 21(1): 123-142.

Glosten, L. R. and P. R. Milgrom (1985). "Bid, ask and transaction prices in a specialist market with heterogeneously informed traders." Journal of Financial Economics, 14(1): 71-100.

Goyenko, R. Y., C. Holden and C. Trzcinka (2009). "Do liquidity measures measure liquidity?” Journal of Financial Economics, 92(2): 153-181.

Hagemann, S. and C. Weber (2013). "An empirical analysis of liquidity and its determinants in the German intraday market for electricity." EWL Working Paper No. 17/2013. Retrived from https://papers.ssrn.com/sol3/papers.cfm? abstract_id=2349565

Harris, L. (2003). "Trading and exchanges: Market microstructure for practitioners.” Oxford University Press.

Hartley, P. R. (2015). "The future of long-term LNG contracts.” The Energy Journal, 36(3): 209-233.

Hasbrouck, J. (1991). "Measuring the information content of stock trades." Journal of Finance, 46(1): 179-207.

Hasbrouck, J. (2007). "Empirical market microstructure: The institutions, economics, and econometrics of securities trading." Oxford University Press.

Hasbrouck, J. (2009). "Trading costs and returns for US equities: Estimating effective costs from daily data." Journal of Finance, 64(3): 1445-1477

Heather, P. (2015). "The evolution of European traded gas hubs.” Oxford Institute for Energy Studies, OIES Paper: NG 104. Retrived from https://www. oxfordenergy.org/wpcms/wp-content/uploads/2016/02/NG-104.pdf.

Huang, R. D. and H. Stoll (1996). "Dealer versus auction markets: A paired comparison of execution costs on NASDAQ and the NYSE." Journal of Financial Economics, 41(3): 313-357.

Huang, R. D. and H. Stoll (1997). “The components of the bid-ask spread: A general approach.” Review of Financial Studies, 10(4): 995-1034.

Intercontinental Exchange. (2017). "UK natural gas futures. Contract specifications." Retrived from https://www. theice com/products/910/UK-Natural-Gas-Futures/specs

International Gas Union. (2016). "Wholesale Gas Price Survey." Retrived from http://www.igu.org/sites/default/ files/node-news_item-field_file/IGU_WholeSaleGasPrice_Survey0509_2016.pdf

Jankowitsch, R., A. Nashikkar and M. G. Subrahmanyam (2011). "Price dispersion in OTC markets: A new measure of liquidity." Journal of Banking \& Finance, 35(2): 343-357.

Kyle, A. (1985). "Continuous auctions and insider trading." Econometrica, 53(6): 1315-1335.

Lee, C. and M. Ready (1991). "Inferring trade direction from intraday data." Journal of Finance, 46(2): 733-746.

Locke, P. and P. Venkatesh (1997). "Futures market transaction costs: Introduction." Journal of Futures Markets, 17(2): 229-245.

Madhavan, A., M. Richardson and M. Roomans (1997). "Why do security prices change? A transaction-level analysis of NYSE stocks.” Review of Financial Studies, 10(4): 1035-1064.

Marshall, B., N. Nguyen and N. Visaltanachoti (2012). "Commodity liquidity measurement and transaction costs." Review of Financial Studies, 25(2): 599-638.

Marshall, B., N. Nguyen and N. Visaltanachoti (2013). "Liquidity commonality in commodities." Journal of Banking \& Finance, 37(1): 11-20

Neuhoff, K., N. Ritter, A. Salah-Abou-El-Enien and P. Vassilopoulos (2016). "Intraday markets for power: Discretizing the continuous trading?" DIW Berlin Discussion Paper No. 1544. Retrived from https://papers.ssrn.com/sol3/ papers.cfm?abstract_id=2723902

Nick, S. (2016). "The informational efficiency of European natural gas hubs: Price formation and intertemporal arbitrage." The Energy Journal, 37(2): 1-30.

Copyright (C) 2016 by the IAEE. All rights reserved. 
Ofgem (2016). “Wholesale Market Indicators.” Retrived from https://www.ofgem.gov.uk/data-portal/ wholesale-market-indicators

O’Hara, M. (1995). “Market microstructure theory.” Blackwell Cambridge, MA.

Pastor, L. and R. Stambaugh (2003). "Liquidity risk and expected stock returns." Journal of Political Economy, 111(3): 642-685.

Payne, R. (2003). "Informed trade in spot foreign exchange markets: an empirical investigation." Journal of International Economics, 61(2): 307-329.

Roll, R. (1984). “A simple implicit mesure of the effective bid-ask spread in an efficient market." Journal of Finance, 39(4): 1127-1139.

Stoll, H. R. (1978). "The supply of dealer services in security markets.” Journal of Finance, 33: 1133-1151.

Stoll, H. R. (1989). "Inferring the components of the bid-ask spread: Theory and empirical tests." Journal of Finance, 44(1): 115-134.

Timera-Energy (2013). "European storage response to the NBP price spike." 8 April, 2013. Retrived from http: //www.timera-energy.com/uk-gas/european-storage-response-to-the-nbp-price-spike/

Timera-Energy (2016). "Rough storage issues remain a structural threat." 29 August, 2016. Retrived from http: //www.timera-energy.com/rough-storage-issues-remain-a-structural-threat

Weber, C. (2010). "Adequate intraday market design to enable the integration of wind energy into European power system." Energy Policy, 38(7): 3155-3163.

Zhang, L., P. A. Mykland and Y. Aït-Sahalia (2005). "A tale of two time scales: Determining integrated volatility with noisy high-frequency data." Journal of the American Statistical Association, 100(472): 1394-1411. 